\title{
Feature
}

\section{Is the world Ready for $100 \%$ Renewable Energy-based Power Generation?}

\author{
Dr Tilak Siyambalapitiya \\ Past President, SLEMA
}

A recent research paper by a respected group of researchers has shaken the professional circles: in short, they concluded that a $100 \%$ renewable energy-based power system is not possible, based on 24 studies they reviewed [1]. A few months later, an equally respected group of scientists refuted the conclusions of the earlier paper[2] and concluded that "energy systems based on renewables, on the other hand, are not only feasible, but already economically viable and decreasing in cost every year" and went on to conclude that "the $100 \%$ renewable energy scenarios proposed in the literature are not just feasible, but also viable".

So, the opinion of the professional world too, is divided. In Sri Lanka too, the same debate is raging, severe at times, softens later. However, there is a difference between how the rest of the professional world debates issues: their debates are based on quantified facts and extensive modelling of renewable energy systems and the power system. Over here in Sri Lanka, the debate is largely based on personal convictions and emotions.

There are many indices with which the technical quality of a power system is measured, largely grouped into indices on reliability and power quality. There are standard indices to measure and report such indices. In Sri Lanka, such indices are not calculated even by researchers; electricity utilities have ignored the government gazette notification in 2017 to begin measuring and reporting reliability and power quality. Therefore, customers are not aware of their present quality of supply and largely accept the quality dished out by the two distributors CEB and LECO, as their fate.

In this backdrop, there are others who propose $100 \%$ indigenous energy or $100 \%$ renewable by such and such a year, entirely based on hearsay such as "when I went up country, I was blown out, and that's where we should be building wind power plants".

\section{The Anatomy of a Blackout}

The date was 27th September 2015 and the time was 11:51 pm. It was a Sunday and a poya day, too. Much of the country was asleep, except the workers manning machines in 24-hour industries, staff providing essential services such as health and security, and of course, the staff at power plants, vital substations and the power system control centre in Colombo 9. The power system was recording a demand of $930 \mathrm{MW}$, somewhat lower than on a typical day, owing to favourable weather that pulled the temperatures down across the country.

One generator at Norochcholai power plant tripped out at 11:51 pm, the reason for which was later found to be an over-sensitive protection device. In the attempt to halt the catastrophic failure, between 11:51 and 11:54 pm, about $40 \%$ of customers were automatically disconnected, but the power system could not be saved. Remaining generators slowed down to release the stored energy in them, to help bridge the gap, but with little success. By 11:54 pm, it was all over. All generators tripped out and the country was in darkness. The frequency (Figure 1) and the voltage went haywire, until the final collapse at the 209th second. Within three minutes from the first event, the power system was gone and dead.

It took four hours to restore the electricity supply to all customers in the country.

Although many "committees" were appointed to investigate the outage and its aftermath, none of their reports were released in the public domain. In any other country, there would have been several workshops organized by the utility to explain what happened; institutions of engineers would organize seminars to discuss; several research projects would be initiated at universities to deeply examine what could have prevented such a collapse. None happened in Sri Lanka; but that is not the subject of my discussion today. 
Figure 1 - The Power System Struggled for 3 minutes and collapsed at the 209

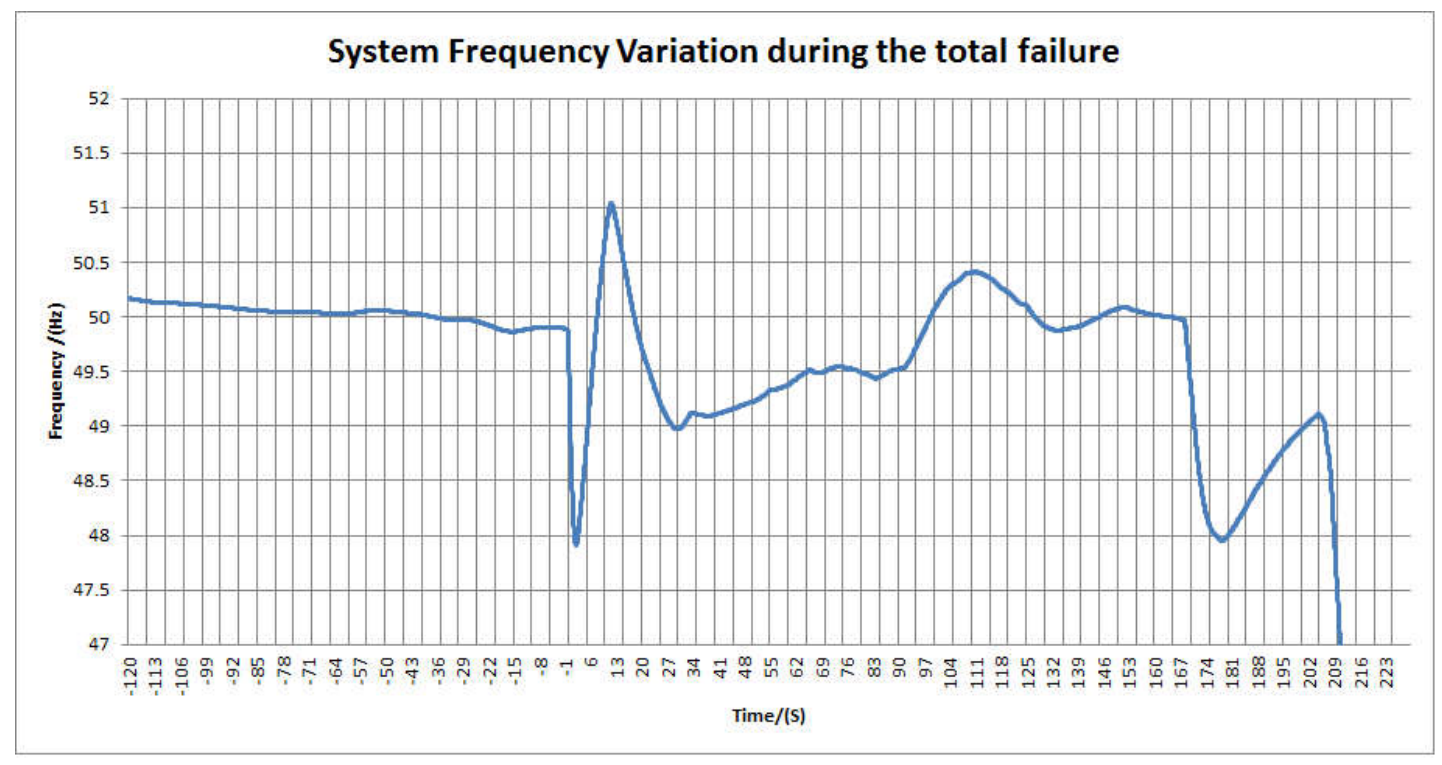

\section{Planning Power Systems is Complex}

Planning and operating an electric power system is a complex task. To be honest, every electric power engineer does not understand all aspects of the utility business: power system planning, construction, operations, economics and finances. Even in the University, many give up the sections on economics; others give-up the sections on stability. Finally, all good electrical engineers in service develop expertise in their chosen area of work, after graduation. Others settle down to do less technically challenging tasks.

In fact, each lecture and tutorial in University finally become useful to a practicing electric power engineer; be it numerical analysis, leastsquare fit, LaGrange principles, the Bellman's principle of optimality; or the equal area criterion. Transient reactance and inertia constant, as well as the operating curve, are dayto-day terms of a power system engineer. Complex numbers, which many engineers simply erase from their memory after university, is day to day work for a power engineer. Advances in technology have so far not been able to let us do away with the fundamental principles of power system design and operation.

Let us come back to the incident of $27^{\text {th }}$ September 2015. That was a serious event. What we do know is that in a live power system, generators trip out all the time. When that happens, the remaining generators pick-up the lost power generating capacity by automatically opening their water valves or fuel valves. That takes a few seconds, typically five seconds. In other words, the time constant of the valves and the associated systems are in the 3 to 8 second range.

Until fuel valves and water valves open, stored kinetic energy in all remaining generators and customer motors would be converted to electricity and released almost instantly. No controls are needed; it happens automatically.

What happens when you start a motor in your factory? Surely you do not telephone the power supplier, CEB or LECO, to tell them that you want to start a motor. There was a time you would have had to do that, but that was about a century ago, when electric power system engineering was in its infancy. Now all those restrictions are gone, and you simply switch it on. Until the fuel valves and water valves open, all generators in the power system slow down, and convert their stored kinetic energy to electrical energy, and allow you to start your motor and run it. Right at the moment you switch it on. Certainly not 5 seconds later.

\section{Just Imagine !}

If there were no rotating generators in the power system with stored kinetic energy? If all the generators are solar photovoltaics (no moving parts), or wind and mini-hydropower (slowmoving parts)? Then the power system has no 
kinetic energy to instantly convert to electrical energy, to allow you to start and run your precious motor. What is more? There are no fuel valves at all in an all-renewable energy system, and water valves are already fully open. So, there is no additional energy that the power supply system can provide in 5 seconds or in 5 minutes, because solar energy and wind energy cannot be stored. Hydropower can be stored in a reservoir, but since the resources are limited, hydropower will supply a diminishing share of electricity demand. So what can we expect when a new motor is started, on the day when the entire power system (as visualized by some) is using only renewable energy?

The power system will simply collapse. First the voltage will drop, and the lowered voltage will cause the renewable energy generators to trip out one by one, until all of them drop out.

So, is there no other way to solve this problem? Well there is; one conventional approach and one novel approach. The conventional approach is to build "pumped storage" power plants. In such power plants, there are two reservoirs, not one. Water is pumped into the upper reservoir when extra power is available. Say during the day when solar power is abundant. (Do not ask me what happens when the water pumping is on and if someone again wants to start a motor! Just believe that every problem has a solution, but at a price). This would require more reservoirs to be built; some of them may not even be associated with existing hydropower plants but will be built brand new. One reservoir above and the other below, both artificial. There will be sacrifices to be made; houses demolished, dams built, tunnels dug, and all the problems that come with such projects, but they can be done.

The second method is to use batteries. That is how electricity was stored in smaller quantities for portable equipment. Now research worldwide has turned on heavier and larger batteries. In theory, batteries can respond very fast, and they are as good as rotating generators, in responding to a sudden demand for power. They can help the grid to meet a generating capacity shortage or a sudden increase in demand. Today, the sudden increase in demand is served first by the rotating generators, followed by opening water valves and fuel valves of all generators that have spare capacity. Both the emergency actions have stored energy of larger quantifies behind it, as water or fuel.
However, a battery cannot absorb fuel or water and give electricity out, like a power plant. It can store electricity and later give electricity out. It cannot provide electricity for a long period, without being fed with electricity.

So it will be some time, may be a few more years or even decades, before limitations in batteries are resolved to at least theoretically enable a $100 \%$ renewable energy grid, that would provide electricity at the same level of reliability and the quality, the modern society expects.

What do we do until then? What shall we get our electricity from?

This is the question that was heavily debated in Sri Lanka over the past two months, to the extent that it triggered a trade-union action by electricity utility engineers. Electrical engineers were pushing for a mix of all the principal sources: coal, gas, hydro, wind, solar and biomass, with limited support from oil. The Public Utilities Commission is alleged to have altered the plan of the utility and approved a plan in which basically coal was replaced with gas, thus making the plan gas-dominant. More on coal and gas later.

\section{Figure 2 - Sri Lanka has about $130 \mathrm{MW}$ of Wind Power Generating Capacity}

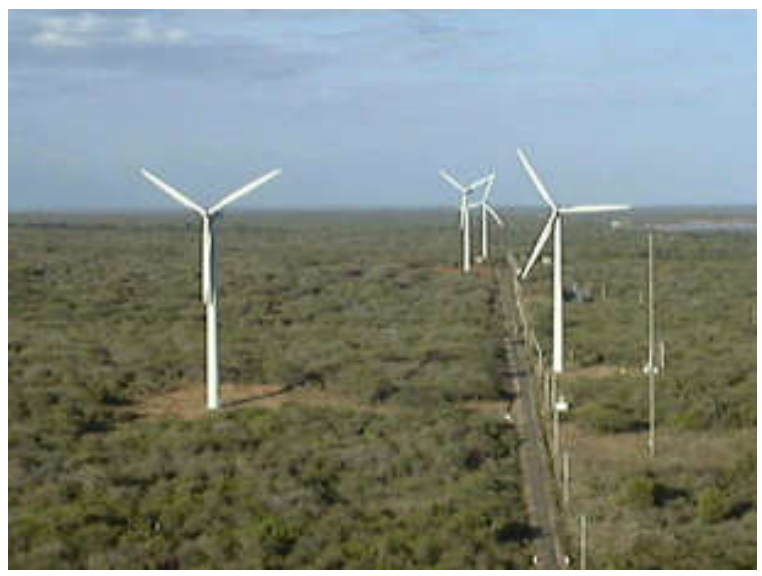

With so many variables, some quantified and others non-quantifiable, determination of the generation plan of a country is a difficult task. Sri Lanka has no open market for power generation. Bangladesh, Pakistan and Nepal are similarly closed markets, but India is in the process of establishing a competitive market. As such, India has de-licensed the power generation business. Both utilities and private sector build power generation, and the private sector gets both 
short-term and long-term contracts. While there is some degree of competition to secure contracts, the system is not entirely transparent or corruption-free. It is not unusual to hear of power generating companies going bankrupt, as they could not get contracts to supply power, after building the power plant.

Sri Lanka does not have a competitive market for power generation. The only competition is when selecting a contractor (for a utility power plant) and when selecting an independent power producer (for a private power plant). Since both types of power plants are effectively "solicited" by the buyer (the CEB), it is logical to continue with the preparation of the long-term generation expansion plan. Once a free market is established, if ever, then the long-term plan may be replaced with a strategic plan. There again, a plan is required because a power system has to produce electricity right at the time it is requested by customers; not before, not after, but right at that moment. There is no other commodity that must be produced right at the time when the customer wants the commodity.

Engineers reading this would certainly have more questions than answers.

Can we not have roof top solar and batteries at home, so that the grid is not required or will standby only to supply when more electricity is required? Yes, of course, it is like keeping a standby generator, and that has a cost. Someone, and that is you (not the poor person who has no solar roof top, no fridge, no fan), must pay that cost, and if not, the investments on the grid will decline and would not be reliable to be a true supplier of last resort.

Figure 2 - The country's solar PV capacity exceeds $200 \mathrm{MW}$, half of it on rooftops

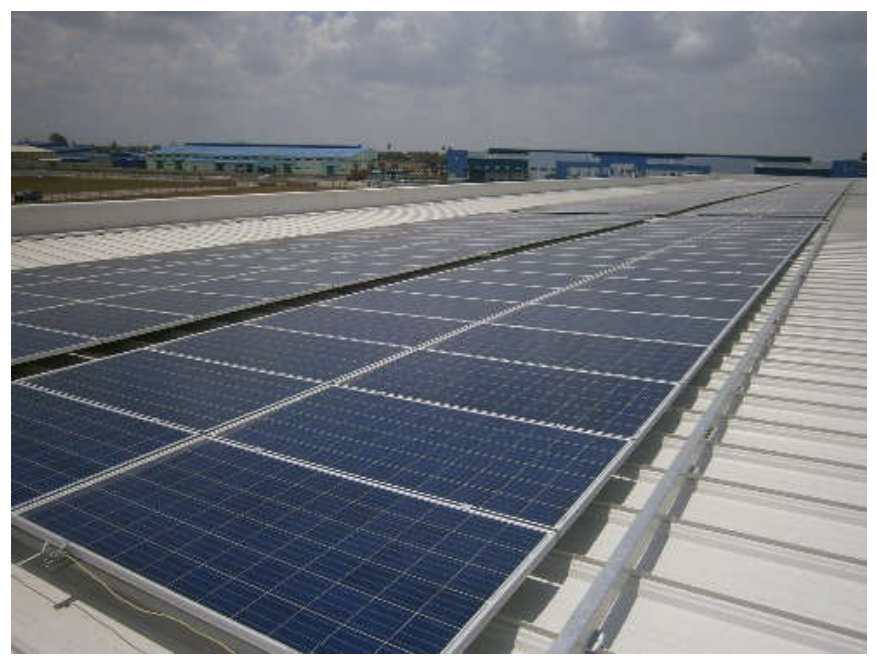

Do you know? One island off Jaffna, "Eluvaithivu" is presently served with electricity entirely from solar PV and wind power. Batteries store during the day and provide electricity in the night. A diesel generator is standing by. Very soon, three more islands off Jaffna, including Nagadeepa, will have similar wind-solar hybrid power systems. The whole system may be considered as a pilot project, to help understand how such systems work.

\section{References}

[1] B.P. Hearda, B.W. Brookb, T.M.L. Wigleya, and C.J.A. Bradshawd, "Burden of proof: A comprehensive review of the feasibility of $100 \%$ renewable-electricity systems", Renewable and Sustainable Energy Reviews 76 (2017) pp1122-1133.

[2] T.W. Browna, T. Bischof-Niemzc, K. Blokd, C. Breyere, H. Lundf, and B.V. Mathieseng "Response to 'Burden of proof: A comprehensive review of the feasibility of $100 \%$ renewableelectricity systems", Renewable and Sustainable Energy Reviews 92 (2018) pp 834-847. 
Correction - The Figure 9 -The Variation of Boiler Steam Generating Cost with Boiler

Exergy Efficiency of "Potential of exergy efficiency improvement of coal power plants in Sri Lanka " paper in SLEMA Journal, Volume 19, No. 2, September 2016, page 22

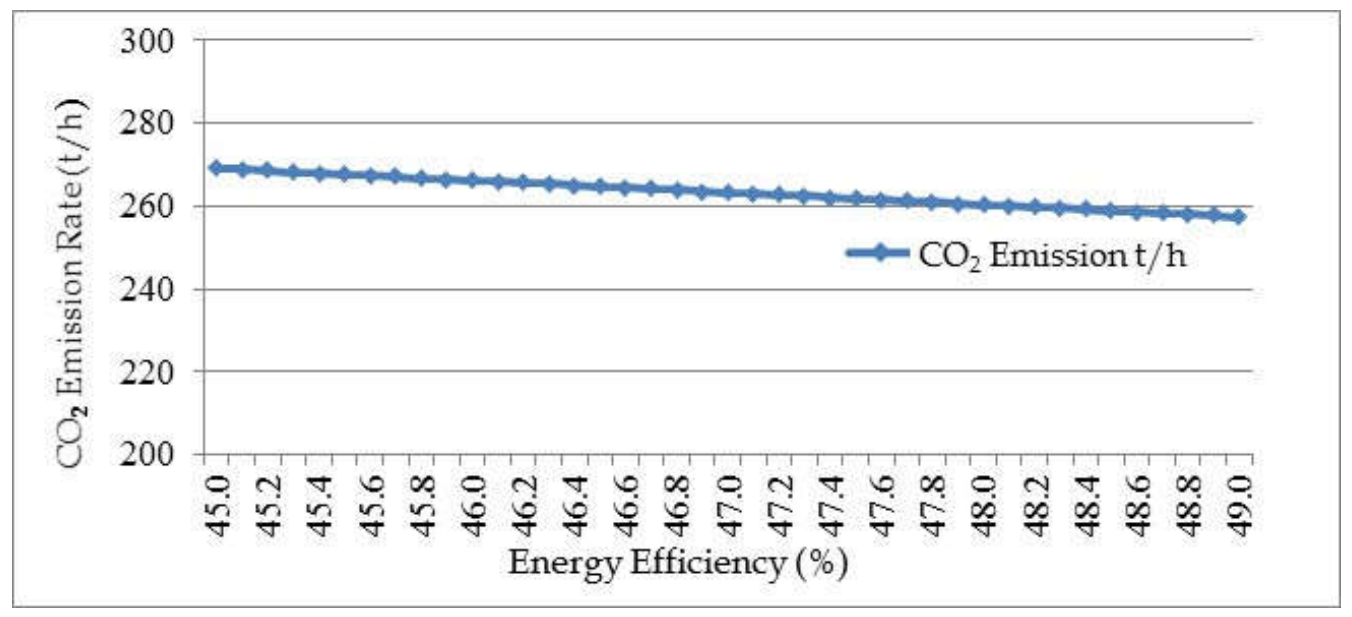

